\title{
TRANSPARENT CONDUCTING COATINGS MADE FROM REDISPERSABLE CRYSTALLINE NANOSCALED POWDERS
}

\author{
C. Goebbert*, H. Bisht*, R. Nonninger**, M. A. Aegerter*, H. Schmidt** \\ * Department of Coating Technology \\ **Department of Chemistry and Technology of Non-metallic Inorganic Materials \\ INM-Institut für Neue Materialien, Im Stadtwald, Gebäude 43, D-66123 Saarbrücken, \\ GERMANY
}

\begin{abstract}
A new wet chemical concept is presented for the preparation of electrically conducting $\mathrm{SnO}_{2}: \mathrm{Sb}$ (ATO) and $\mathrm{In}_{2} \mathrm{O}_{3}: \mathrm{Sn}$ (ITO) coatings. It is based on the deposition by spin, dip or spray techniques of a solution containing crystalline nanoscaled particles fully redispersable in a solvent. The particle synthesis is carried out in a solution at temperatures $<200{ }^{\circ} \mathrm{C}$ by a controlled growth reaction using $\mathrm{SnCl}_{4}$ and $\mathrm{InCl}_{3}$ as precursors and $\mathrm{SbCl}_{3}$ and $\mathrm{SnCl}_{4}$ as dopant, respectively. The aggregation of the particles is avoided by in-situ surface modification with bifunctional organic molecules. After drying the nanocrystalline particles can be fully redispersed in ethanol at $\mathrm{pH}<6$ (for ITO) or water at $\mathrm{pH}>8$ (for ATO) with solid contents up to $8.8 \mathrm{vol}$. \%. Single layers with thickness up to $200 \mathrm{~nm}$ (ATO) and $400 \mathrm{~nm}$ (ITO) have been fabricated. Their sheet resistance decrease with the sintering temperature. Typical lowest values are $430 \Omega_{\square}\left(550^{\circ} \mathrm{C}\right)$ for ATO and $90 \Omega_{\square}\left(900^{\circ} \mathrm{C}\right)$ for reduced ITO. The resistivity of as fired ATO and ITO coatings is stable but it slightly increases with time for ITO in the reduced state. All coatings have a transmission in the visible range of about $90 \%$. Anti-glare conducting coatings on glass with $70 \mathrm{GU}$ as well as antistatic coatings $\left(\mathrm{R}_{\square} \approx\right.$ $1 \mathrm{M} \Omega_{\square}$ ) on polycarbonate substrates have been obtained with chemically modified ITO suspensions.
\end{abstract}

\section{INTRODUCTION}

Transparent conducting oxides deposited on glass are important materials in the field of optoelectronic devices such as electrochromic windows, solar cells, electroluminescence and liquid crystal displays [1]. N-type semiconductors such as indium tin oxide (ITO), fluorine or antimony doped tin dioxide (FTO, ATO) or aluminium or gallium doped zinc oxide (AZO, GZO) are widely used as transparent electrodes in these applications. Practically all known coating processes have been used for their preparation [1,2].

The coatings obtained by the sol-gel route present a resistivity, $\rho$, higher than those obtained by other processes. Typical values reported are $3 \cdot 10^{-3} \Omega \mathrm{cm}[3,4]$ for $\mathrm{SnO}_{2}: \mathrm{Sb}$ coatings and $8 \cdot 10^{-4} \Omega \mathrm{cm}$ for $\operatorname{In}_{2} \mathrm{O}_{3}:$ Sn coatings [5]. The reason for the low conductivity of such coatings is due to their high porosity (low density) even after sintering at high temperature [6]. Structures with large and densely packed crystallites obtained by spray pyrolysis, sputtering and CVD processes exhibit higher electron mobility and carrier density and consequently lower resistivity [1].

The paper discusses a new concept for the preparation of ATO and ITO coatings on glass and plastic substrates based on the use of solutions containing already crystalline fully redispersed $\mathrm{SnO}_{2}: \mathrm{Sb}$ or $\mathrm{In}_{2} \mathrm{O}_{3}: \mathrm{Sn}$ nanoparticles. The influence of the densification temperature and sintering time on the resistivity as well as the long time stability of the coatings are examined. 


\section{EXPERIMENTAL}

The preparation of transparent coatings by wet chemical processes using crystalline powders is possible if stable suspensions of particles with sufficiently small size $(<100 \mathrm{~nm})$ can be obtained. In conventional synthesis, particulate systems minimize their surface free energy by growing into larger particles and forming larger agglomerates which are difficult to be redispersed. These reactions can be avoided by controlling the growth of the particles during the precipitation process and by adjusting the particles surface free energy by in-situ surface modification. The basic principle of this concept is shown in figure 1. It has been applied to many oxide materials $[7,8,9]$.

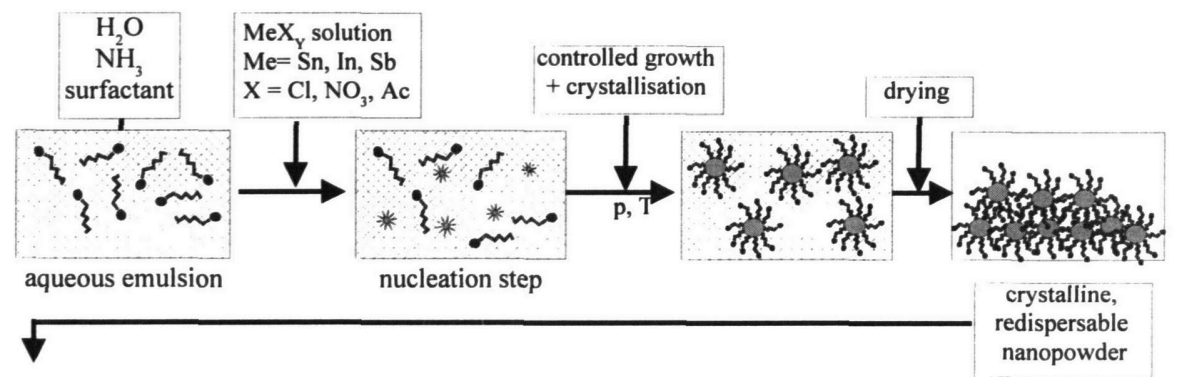

Processing A

heat treatment

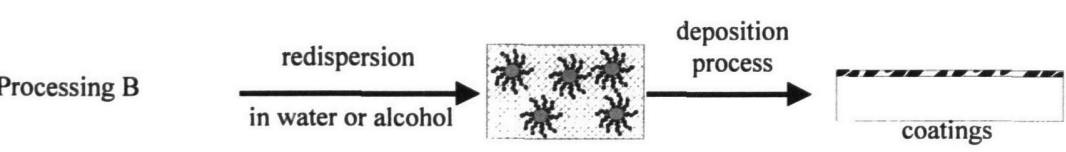

Fig. 1: Concept of the preparation and the use of crystalline nanoparticles using a controlled growth reaction.

The preparation of ATO and ITO nanoscaled powders was carried out by adding dropwise an ethanolic solution of tin(IV)chloride or indium(III)chloride containing $0.1-10$ mole $\%$ of $\mathrm{SbCl}_{3}$ or $\mathrm{SnCl}_{4}$, respectively, to an aqueous ammonia solution containing $\beta$-alanine, a surface modifying agent. The ATO suspensions were hydrothermally treated at $150{ }^{\circ} \mathrm{C}$ under $10 \mathrm{bar}$ for 3 hours and the ITO suspensions at $80^{\circ} \mathrm{C}$ for 24 hours under atmospheric pressure. The resulting powders were isolated by centrifugation, washed with water several times and then dried at $60^{\circ} \mathrm{C}$. The dried ITO powder was further annealed at $250^{\circ} \mathrm{C}$ in a reducing atmosphere. The powders were characterised by High Resolution Transmission Electron Microscopy (HRTEM (CM200 FEG, Philips) and x-ray diffraction (D500, Siemens). The crystallite size was calculated using the Siemens software.

Colloidal suspensions of ATO were prepared by redispersing the dried powder in water at $\mathrm{pH} \geq 9$ using tetramethylammoniahydroxide as dispersion agent. The suspensions were then treated under ultrasonic irradiation for 2 minutes and stirred during 1 day. The solutions are clear with a yellowish orange colour and no evidence of precipitation could be found during several months with a solid content up to $8,8 \mathrm{vol}$. \%.

Dried ITO powder was mechanically redispersed in a mixture of ethyleneglycol and a carbon acid as dispersion agent and the solution was then added to ethanol or water. The suspensions showed a blue colour and are stable (no precipitation) during several month with 
solid contents up to $6,2 \mathrm{vol}$. \%.

Both suspensions were characterised by measurements of the zeta potential (Zetasizer, Malvern) and the hydrodynamic particle size (Ultrafine Particle Analyzer).

ATO coatings were deposited on clean borofloat substrates by spin coating process $(2000 \mathrm{rpm}, 15 \mathrm{~s})$. ITO films were prepared by dip coating clean silica or borosilicate substrates at a withdrawal speed of $3 \mathrm{~mm} / \mathrm{s}$. The thermal densification of the films was carried out in a furnace in air up to $900^{\circ} \mathrm{C}$. ITO coatings were also annealed afterwards in a $\mathrm{N}_{2}$ atmosphere at a temperature of $300^{\circ} \mathrm{C}$ in order to decrease their resistivity.

Anti-glare coatings have been obtained with an ITO suspension modified with an alkoxysilane by a room temperature spraying process and then sintered at higher temperature.

In order to coat plastic substrates the ITO suspension was modified by adding up to $40 \mathrm{wt}$. \% organofunctionalized silanes and a photostarter. These additives allow to polymerise and harden the layer by UV irradiation at room temperature.

The following characteristics of the coatings were measured: sheet resistance (4 pointtechnique), film thickness and roughness (P10 surface profiler, Tencor), abrasion according to MIL specification $675 \mathrm{C}$ (shear/scratch tester, model 502, Teledyne Taper), optical reflection and transmission (Cary 5E, Varian) and gloss (micro-TRI-gloss, BYK, Gardner).

\section{RESULTS AND DISCUSSION}

\section{Powder and sol characterisation}

The structure of dried $\mathrm{SnO}_{2}, \mathrm{SnO}_{2}: \mathrm{Sb}$ and $\mathrm{In}_{2} \mathrm{O}_{3}: \mathrm{Sn}$ powders is shown in figure 2. The particles of all materials are already crystalline and have a cassiterite structure for $\mathrm{SnO}_{2}$, $\mathrm{SnO}_{2}: \mathrm{Sb}$ and a cubic $\mathrm{In}_{2} \mathrm{O}_{3}$ phase for the ITO powder. The TO, ATO and ITO crystallites are not oriented. The crystallite size calculated from the (110) peak, is $7 \mathrm{~nm}$ for $\mathrm{SnO}_{2}$ and $3 \mathrm{~nm}$ for $\mathrm{SnO}_{2}: \mathrm{Sb}(5$ mole \% Sb). A systematic decrease of the crystallite size was observed with increasing antimony content. The crystallite size of $\operatorname{In}_{2} \mathrm{O}_{3}: \mathrm{Sn}$ calculated with the (222) peak is $15 \mathrm{~nm}$.

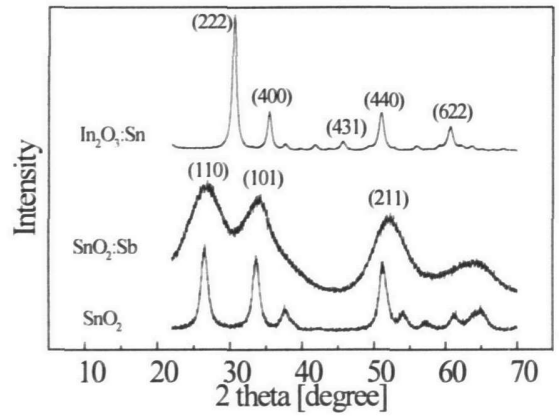

Fig. 2: X-ray diffraction of dried, nanoscaled, crystalline $\mathrm{SnO}_{2}, \mathrm{SnO}_{2}: \mathrm{Sb}$ and $\mathrm{In}_{2} \mathrm{O}_{3}: \mathrm{Sn}$ powder prepared by a controlled growth reaction. The lattice coordinates correspond to the data of the JCPDS database: ATO: table 41-1445, cassiterite structure and ITO: table 06-416, cubic indiumoxide structure.

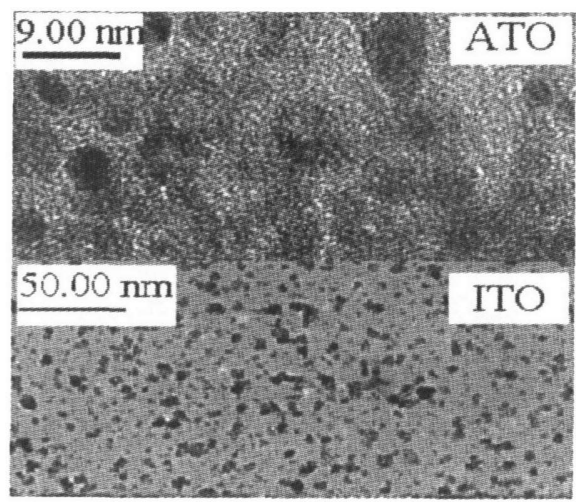

Fig. 3: HRTEM picture of crystalline $\mathrm{SnO}_{2}: \mathrm{Sb}$ nanopowder redispersed in water with TMAH as dispersion agent $(\mathrm{pH}=10)$ and $\mathrm{In}_{2} \mathrm{O}_{3}: \mathrm{Sn}$ nanopowder after annealing and redispersion in ethanol $(\mathrm{pH}=4)$. 
The water based ATO suspensions are stable for $\mathrm{pH}>8\left(\mathrm{pH}_{\text {iep }}=3.7\right)$ and the mean hydrodynamic particle size is $4 \mathrm{~nm}$. ITO suspensions are stable for $\mathrm{pH}<6\left(\mathrm{pH}_{\mathrm{iep}}=8.5\right)$ and the mean hydrodynamic particle size is $11 \mathrm{~nm}$. The average values are identical to the values of the crystallite size determined from the x-ray measurement and indicate that the particles are fully dispersed down to the primary particle size and that each particle appears to be formed by a single crystallite. The particle size distribution is monomodal and their width is narrow.

\section{Film characterisation}

Single ATO layers with thickness of $200 \mathrm{~nm}$ have been prepared using an aqueous dispersion of ATO particles with a solid content of $6.25 \mathrm{vol} . \%$, while $400 \mathrm{~nm}$ thick single layer have been obtained with an ITO suspension of $3.25 \mathrm{vol} . \%$ solid content. Both coatings have no visible cracks and are very homogeneous. The resistivity and sheet resistance of $400 \mathrm{~nm}$ thick ATO (2 layers) and ITO (1 layer) coatings are shown in figure 4 as a function of the sintering temperature. The values steadily decrease with the increase of the temperature. For ATO coating $\rho$ reaches a minimum $\rho=1.7 \cdot 10^{-2} \Omega \mathrm{cm}\left(R_{\square}=430 \Omega_{\square}\right)$ at $550{ }^{\circ} \mathrm{C}$ while the resistivity of ITO coatings decreases continuously down to $\rho=1.5 \cdot 10^{-2} \Omega \mathrm{cm}\left(R_{\square}=380 \Omega_{\square}\right)$ at $900{ }^{\circ} \mathrm{C}$. A postannealing of ITO coatings in nitrogen at a temperature of $300{ }^{\circ} \mathrm{C}$ reduces further the resistivity and a value as small as $\rho=3.4 \cdot 10^{-3} \Omega \mathrm{cm}\left(R_{\square}=90 \Omega_{\square}\right)$ is obtained for coatings sintered at $900{ }^{\circ} \mathrm{C}$.

The transmission of all coatings in the visible range measured against air is about $90 \%$. This reflects the beneficial effect of using particles in the nanometer range for coating production as these particles practically do not scatter the visible light. The annealed ITO and ATO coatings show a similar increase of the reflectance in the IR range due to the conducting properties of the materials. However, the as deposited ITO film has a lower reflectance due to the lower density of the electrons.

Deposition and heating conditions have a strong influence on the morphology of the coatings. Each layer of single and multilayer coatings obtained with a sol containing crystalline nanoparticles are composed of small crystallites and presents a thin $(<10 \mathrm{~nm})$ dense interface (external part) lying on top of a more porous material (internal part). The surface of ATO coatings is smoother $\left(R_{a}=0,4 \mathrm{~nm}\right)$ than the surface of ATO and ITO coatings made by sol-gel or sputtering technique $\left(\mathrm{R}_{\mathrm{a}}=2,0 \mathrm{~nm}\right)$. This is due to the very small particles $(4 \mathrm{~nm})$ used to obtain the coatings.

Due to the porosity of the layers the electrons are scattered at the grain boundaries of the particles, leading to low mobility and a relatively high resistivity. The particulate nature of the ATO and ITO layers explains why the resistivity is still a factor 10 (for ITO) and 100 (for ATO) higher than that of coatings prepared by physical techniques.

The UV cured ITO coatings deposited on PC substrates exhibit a sheet resistance of $1.1 \cdot 10^{6} \Omega_{\square}$, conferring antistatic properties to the system. The UV radiation time and the concentration of GPTS and MPTS have no detectable effect on the sheet resistance of the coatings. 


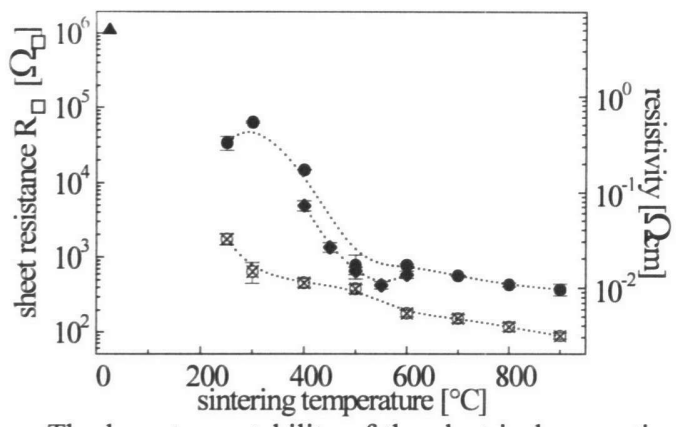

Fig. 4: Sheet resistance (left) and resistivity (right) of $400 \mathrm{~nm}$ thick ATO und ITO coatings vs sintering temperature (30 $\mathrm{min})$ : as deposited ATO ( $)$, as deposited ITO (•), ITO annealed in a nitrogen atmosphere at $300{ }^{\circ} \mathrm{C}(\otimes)$, ITO deposited on plastic cured under UV radiation at room temperature for $3 \min (\boldsymbol{\Delta})$.

The long term stability of the electrical properties of as sintered ITO films during storage in air at $20^{\circ} \mathrm{C}$ and $40 \%$ relative humidity and during a continuous storage at $900{ }^{\circ} \mathrm{C}$ is shown in figure 5. The sheet resistance of as sintered coatings remain practically constant. Particularly remarkable is the fact that no damage has been observed during the high temperature test which suggests a possible use of such coatings for continuous high temperature applications. At higher temperature $\left(>900^{\circ} \mathrm{C}\right)$, the ITO slowly starts the decompose to $\mathrm{In}_{2} \mathrm{O}$ and $\mathrm{O}_{2}$, which leads to the increase of the resistivity [10].The resistivity slightly increases with time for $\mathrm{N}_{2}$ annealed ITO coatings. After 40 days, $\rho$ reaches a constant value almost 3 times higher than the value measured immediately after annealing. This is due to the porosity of the layers. Oxygen from the surrounding air diffuses into the coatings through the pores and partly eliminates the effect of the annealing.

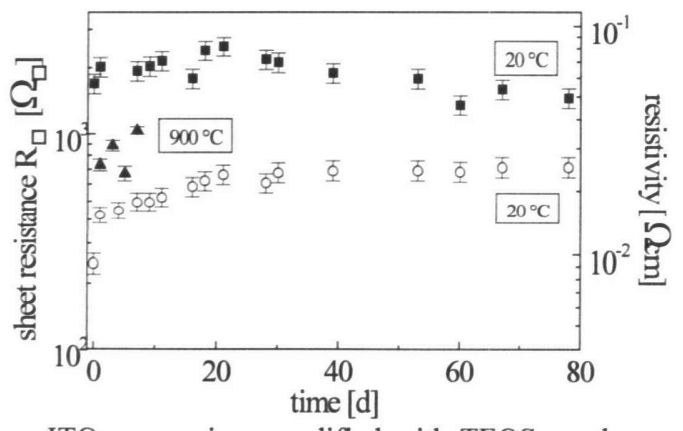

Fig. 5: Time variation of the resistivity of ITO coatings:

() as deposited sintered at $550^{\circ} \mathrm{C}$ and stored in air at $20^{\circ} \mathrm{C}, \mathrm{RH}=40 \%$ (O) sintered at $550{ }^{\circ} \mathrm{C}$, reduced in $\mathrm{N}_{2}$ at $300{ }^{\circ} \mathrm{C}$, stored in air at $20{ }^{\circ} \mathrm{C}, \mathrm{RH}=40 \%$ )

(A) measured in air at $20^{\circ} \mathrm{C}$ after continuous storage at $900^{\circ} \mathrm{C}$

ITO suspensions modified with TEOS can be sprayed on glass at room temperature and show after heating at $550^{\circ} \mathrm{C}$ anti-glare properties with a gloss unit of 68 (measured at $60^{\circ}$ ) (figure 6).

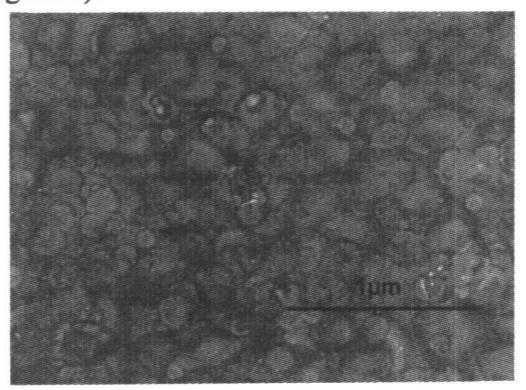

Fig. 6: Surface of an antiglare coating on glass made from a modified ITO suspension, and sprayed at room temperature. The coating was sintered at $550{ }^{\circ} \mathrm{C}$ and has $68 \mathrm{GU}$. 


\section{CONCLUSION}

Crystalline $\mathrm{SnO}_{2}, \mathrm{SnO}_{2}: \mathrm{Sb}$ (ATO) and $\mathrm{In}_{2} \mathrm{O}_{3}: \mathrm{Sn}$ (ITO) nanoparticles fully redispersable in water or ethanol have been prepared. Transparent conducting coatings with thickness up to $400 \mathrm{~nm} /$ layer for ITO and $200 \mathrm{~nm} /$ layer for ATO have been obtained by spin coating (ATO, ITO) and dip coating (ITO) process. For ATO the lowest resistivity value, $\rho=1.7 \cdot 10^{-2} \Omega \mathrm{cm}$, was obtained at a sintering temperature of $550^{\circ} \mathrm{C}$ while for ITO layers the lowest resistivity $\rho=2 \cdot 10^{-2} \Omega \mathrm{cm}$ was obtained after sintering at $900{ }^{\circ} \mathrm{C}$. This value was reduced to $\rho=3.4 \cdot 10^{-3} \Omega \mathrm{cm}$ after annealing at $300{ }^{\circ} \mathrm{C}$ in nitrogen atmosphere. All resistivity values are higher than those obtained by sputtering, spray pyrolysis and CVD process. This is due to the porous, particulate morphology of the the layers. The electrical properties of as sintered ATO and ITO coatings are stable under normal conditions $\left(20^{\circ} \mathrm{C}, 40 \% \mathrm{RH}\right.$, tested up to 80 days) and also under high temperature continuous use. The resistivity of reduced ITO coatings, however, slightly increases with time at $20^{\circ} \mathrm{C}$.

Conductive antiglare coatings on glass with a gloss unit of ca. 70 as well as antistatic coatings on polycarbonate substrates with a sheet resistance $R_{\square} \approx 1 M \Omega_{\square}$ have been prepared using modified nanoparticulate sols.

The use of crystalline ATO and ITO nanopowders offers a new way to produce large transparent conducting coatings on PC substrates for antistatic application and on glass substrates for devices requiring conductive, transparent or antiglare coatings with sheet resistance larger than about $300 \Omega_{\square}$ such as touch screen panels, CRT tubes, etc.

\section{ACKNOWLEDGMENT}

This work was financed by the BMBF $(2 \mathrm{~A} 67 / 03 \mathrm{~N} 9040)$ and the State of Saarland (Germany). The authors are grateful to Dr. T. Krajewski for the preparation of the HRTEM images.

\section{REFERENCES}

[1] H. L. Hartnagel, A. L. Dawar, A. K. Jain and C. Jagdish, Semiconducting Transparent Thin Films, IOP Publishing, (Bristol and Philadelphia 1995).

[2] K. L. Chopra, S. Major and D. K. Pandya, Thin Solid Films 102, 1 (1983).

[3] C. Terrier, J. P. Chatelon, R. Berjoan and J. A. Roger, Thin Solid Films 263, 37 (1995).

[4] W. Lada, A. Deptula, T. Olczak, W. Torbicz and D. Pijanowska, J. Sol-Gel Sci. Tech. 2, 551 (1994).

[5] R. B. H. Tahar, T. Ban, Y. Ohya and Y. Takahashi, J. Appl. Physics 83, 2631 (1998).

[6] G. Gasparro, J. Puetz, D. Ganz and M. A. Aegerter, Solar Energy Materials \& Solar Cells, 54, 287 (1998).

[7] D. Burgard, C. Kropf, R. Nass and H. Schmidt in Better Ceramics through Chemistry, edited by A. K. Cheetham, C. J. Brinker, M. L. Mecartney, C. Sanchez (Mater. Res. Soc. Proc. 346, Pittsburgh PA 1994) pp 101 - 107.

[8] C. Goebbert, M. A. Aegerter, D. Burgard, R. Nass and H. Schmidt, J. Mater. Chem. 9, 253-8 (1999).

[9] C. Goebbert, M. A. Aegerter, D. Burgard, R. Nass and H. Schmidt in Chemical and pyrolytic routes to nanostructured powders and their industrial application, edited by G. Beaucage, J. E. Mark, G. T. Burns, D.-W. Hua (Mater. Res. Soc. Proc. 520, Pittsburgh PA 1998) pp 293 - 304.

[10] H. Luckmann, Z. anorg. Ch. 172, 365 (1928). 